
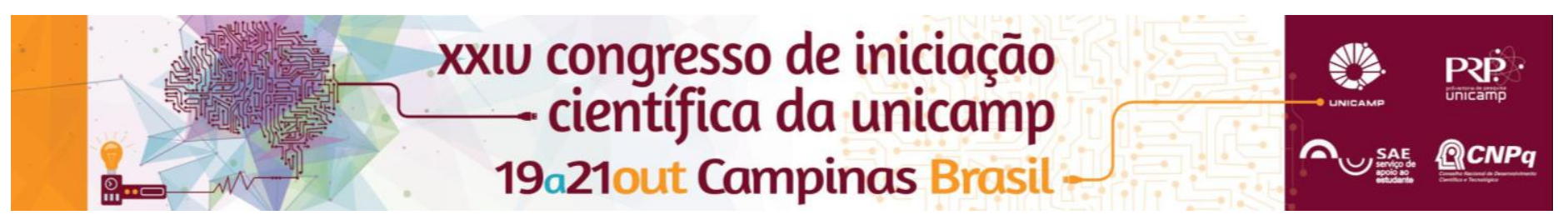

\title{
Prospecção do impacto das ferramentas de software criadas pela DSPGeo nas diversas etapas da cadeia de upstream para prospecção de Óleo e Gás
}

\section{Tainá Souza}

\section{Resumo}

Nesse projeto foi realizada uma análise do impacto mercadológico das ferramentas de software desenvolvidas pela empresa DSPGeo, na cadeia de exploração e produção de petróleo e gás. Procurou-se identificar a possibilidade de inovações internas na DSPGeo, relacionadas a novos mercados, não considerados atualmente, como o uso dos softwares para dados prestack no setor de energia geotérmica. Consequentemente, efetuou-se um estudo de viabilidade técnico-econômica para uma melhor tomada de decisão relacionada às alterações das ferramentas existentes e suas novas aplicações, assim como do desenvolvimento de uma nova ferramenta de acordo com a necessidade do mercado.

\section{Palavras-chave:}

Processamento sísmico, óleo e gás, método CRS

\section{Introdução}

A sísmica de reflexão tem sido o método de levantamento mais utilizado na indústria do petróleo atualmente, pois fornece alta definição das características geológicas em subsuperfície ${ }^{1}$. A empresa DSPGeo atua na fase da prospecção sísmica, no processamento de dados sísmicos de reflexão, pesquisando e desenvolvendo técnicas de processamento de sinal e inteligência computacional. Há a necessidade de avaliações técnico-mercadológicas de possíveis adaptações das soluções DSPGeo para outras etapas da cadeia de petróleo, assim como para outros setores energéticos.

\section{Resultados e Discussão}

A DSPGeo possui dois produtos disponíveis no mercado: - software DSPGeo Stack 2D que produz seções sísmicas empilhadas baseadas no método CRS (Common-Reflection Surface) e o software DSPGeo Data Enhancement 2D, que realça a razão sinal-ruído e regulariza os traços dos dados sísmicos não processados. Um exemplo de imagem com 3 Common midpoints (CMPs) antes e depois do processamento sísmico pode ser visto na figura 1.


Figura 1. A) 3 CMPs de dados não processados. B) 3 CMPs processados com DSPGeo Data Enhancement.

Para ambientes onde há limitantes naturais ou a razão sinal-ruído dos dados pré-empilhados é baixa, o método CRS possibilita a geração de uma imagem com maior DOI: 10.19146/pibic-2016-51783 detalhamento e qualidade. Notou-se, assim, que as ferramentas da DSPGeo poderiam ser utilizadas para levantamentos de áreas onde há potencial geotérmico, geralmente áreas urbanas com presença de ruídos muito altos permanentes de diferentes fontes ${ }^{2}$. Pois esse tipo de dado sísmico requer técnicas de processamento mais eficientes como as realizadas pelo método CRS.

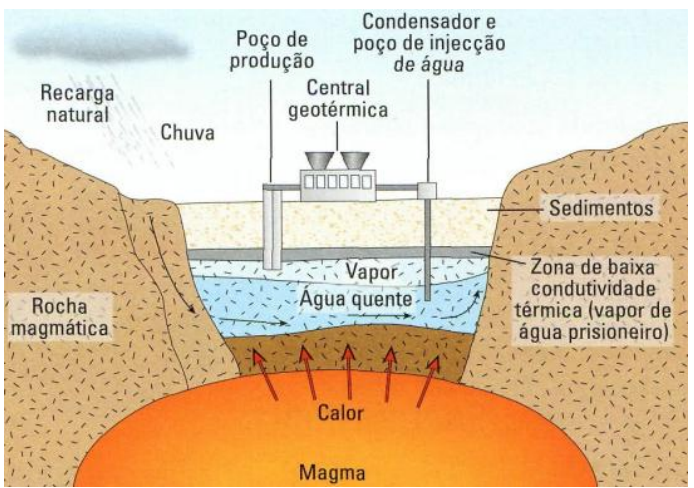

Figura 2. Exemplo de uma central geotérmica.

\section{Conclusões}

Visto que as adaptações necessárias para a aplicação dos softwares DSPGeo no setor de energia térmica seriam apenas mercadológicas e não técnicas, esta foi identificada como sendo a principal possibilidade de alteração na empresa.

\section{Agradecimentos}

Agradeço ao meu orientador, Prof. Renato da Rocha Lopes, ao Everton Nadalin e Yakov Nae, da DSPGeo, e também ao PIBITI/CNPq pela oportunidade de desenvolver esse trabalho.

${ }^{1}$ Almeida, E. L. F.. Dinâmica Tecnológica das Indústrias Energéticas: Apostila Didática. Instituto de Economia, UFRJ, 2004.

${ }^{2}$ Moeck, I., Stiller, M., Pussak, M., Meinert, P., Bauer, K., Bredel-Schürmann, S., Hauptmann, M.: Geothermal Exploration in Megacities - Results from Reflection Seismic Surveying in Berlin (Germany) - Proceedings, World Geothermal Congress, 2015 